\title{
Comparison between AJCC 8th prognostic stage and UICC anatomical stage in patients with primary breast cancer: a single institutional retrospective study
}

\author{
Ryo Tanaka ${ }^{1,2} \cdot$ Yoji Yamagishi $^{1,3} \cdot$ Tomomi Koiwai $^{3} \cdot$ Takako Kono $^{1} \cdot$ Makiko Fukumura-Koga $^{3} \cdot$ Takahiro Einama $^{3}$. \\ Tamio Yamasaki $i^{3} \cdot$ Kimiya Sato $^{1} \cdot$ Hideki Ueno $^{3} \cdot$ Yoji Kishi $^{3} \cdot$ Hitoshi Tsuda $^{1}$
}

Received: 25 February 2020 / Accepted: 20 May 2020 / Published online: 3 June 2020

(c) The Author(s) 2020

\begin{abstract}
Background The 8th edition American Joint Committee on Cancer (AJCC) proposed a prognostic stage (PS), which included not only anatomical factors, but also biological factors. We aimed to investigate the clinicopathological significance of the PS and to compare PS and anatomical stage (AS) that has been established by the Union for International Cancer Control (UICC). Methods Between 2002 and 2017, 800 patients were included in the study. Patients were classified using pathological UICC AS and pathological AJCC PS. The usefulness of PS in comparison with AS was validated using the Akaike information criterion (AIC) and Harrell concordance index (C-index).

Results A total of 401 (50.1\%) patients had pathological AS I, 324 (40.5\%) had AS II, and 75 (9.4\%) had AS III. Meanwhile, 535 (66.8\%) had pathological PS I, 163 (20.4\%) had PS II, and 102 (12.8\%) had PS III. The number of AS II cases was 1.99-fold higher than that of PS II cases. For each stage, these survival curves were almost similar between AS and PS classification. Therefore, many patients to be classified into stage I and stage III were included in AS II group, while many patients to be classified into stage II were included in AS I group. To trichotomize the survival groups, PS appeared to be more specific than AS, and AIC and C-index confirmed the speculation.

Conclusion For the prognostication of primary breast cancer patients, AJCC PS appeared to be able to stratify the cases more appropriately than UICC AS.
\end{abstract}

Keywords AJCC 8th edition · Prognostic stage $\cdot$ Primary breast cancer

Ryo Tanaka and Yoji Yamagishi authors equally contributed as the first author.

Electronic supplementary material The online version of this article (https://doi.org/10.1007/s12282-020-01115-x) contains supplementary material, which is available to authorized users.

Hitoshi Tsuda

hstsuda@gmail.com

1 Department of Basic Pathology, National Defense Medical College, 3-2 Namiki, Tokorozawa, Saitama 359-8513, Japan

2 National Defense Medical College, 3-2 Namiki, Tokorozawa, Saitama 359-8513, Japan

3 Department of Surgery, National Defense Medical College, 3-2 Namiki, Tokorozawa, Saitama 359-8513, Japan

\section{Introduction}

Breast cancer is the most frequent malignant disease, the number of the patients who were newly diagnosed with breast cancer was 1.8 million, and 471,000 died of breast cancer in 2013 [1]. Tumor staging system codified by Union for International Cancer Control (UICC) started in 1933, and is maintained by both the UICC and American Joint Committee on Cancer (AJCC). This system was based on the anatomical factors [primary tumor (T), regional lymph node $(\mathrm{N})$, and distant metastasis $(\mathrm{M})]$, and called the TNM classification system or anatomical stage (AS).

The AS has been used worldwide for various purposes, e.g., standardization of treatment, and for comparison of patient's outcomes based on the common criteria [2]. The primary objective of the UICC AS was to provide a name to an initially diagnosed breast cancer and prevent apparent useless therapy. The past recommendations for most systemic 
therapies, especially chemotherapy, had been based on the status of regional lymph nodes and the primary tumor size [3, 4].

However, in the era of worldwide use of endocrine therapy and molecular targeted therapy, the use of UICC AS alone does not appear sufficient to decide which kind of an adjuvant therapy or a neoadjuvant systemic therapy should be used. The evolving knowledge of breast cancer biology suggests that the status of tumor biomarkers should be documented by the time of initial therapy. These biomarkers included tumor grade, estrogen receptor (ER), progesterone receptor (PgR), and human epidermal growth factor receptor 2 (HER2), and are used for the prediction of prognosis. Tumor grade, which includes histological grade (HG) and nuclear grade (NG) [5-8], is the most reliable and widely used for evaluating tumor differentiation and for selecting the appropriate adjuvant chemotherapy. Hormone receptor status and HER2 status were also useful for predicting the therapeutic effect of the endocrine therapy and HER 2 targeted therapy, respectively [9-12]. The selection of optimal treatment based on these biological factors has become more important [13].

American Joint Committee on Cancer (AJCC), 8th edition established a prognostic stage (PS) classification that not only included anatomical factors ( $\mathrm{T}, \mathrm{N}$, and $\mathrm{M}$ ), but also biological factors (tumor grade, ER, PgR, and HER2) in 2016 [2]. Using the PS classification, it may possible to choose more effective systemic therapies and to predict patient's outcome more accurately compared with the use of $\mathrm{T}, \mathrm{N}$, and $\mathrm{M}$ factors only.

There are two widely used AS classifications: clinical AS is basically determined before the initial treatment. Pathological AS is determined based on the histopathological findings of surgically resected specimens. Likewise, in PS classification, two systems, clinical PS and pathological PS, are considered.

This study aimed to investigate the utility of pathological PS by comparing it with pathological AS in a single-institution cohort. Using the cohort, we statistically compared the fitness as a model and accuracy of prognosis predictability between pathological PS and pathological AS.

For tumor grading, it is recommended to use HG by the World Health Organization classification, 5th ed. [14], but in Japan, NG is also recommended in the General Rules for Clinical and Pathological Recording of Breast Cancer, 18th ed. [15]. Therefore, we classified breast cancer cases not only into PS using HG but also into PS using NG in order to reveal if there are differences in prognostic impact between pathological AJCC PS and pathological PS using NG.

\section{Materials and methods}

\section{Eligible patients}

Between January 2002 and December 2017, radical surgery was performed for the 1159 patients who were diagnosed as histologically primary carcinoma of the breast. Of these, 359 patients were excluded from this study because of (1) the history of malignant diseases other than breast cancer within 5 years $(n=32)$, (2) preoperative chemotherapy or endocrine therapy $(n=138)$, (3) previous treatment of ipsilateral or contralateral breast cancer $(n=108),(4)$ pStage 0 $(n=59)$ and Stage IV $(n=5),(5)$ pTis with node metastases (pN2a) $(n=1),(6)$ incomplete information of any one of pT, pN, M, ER, PgR, HER2, HG and NG $(n=115)$, and/or (7) HER2 equivocal cases $(n=11)$. Of these, 59 patients were excluded because of two or more condition of (1) through (7). Finally, 800 patients were eligible.

\section{Histological study}

Two observers (H.T. or T.K. and Y.Y.) performed the pathological diagnosis. We prepared two PS classifications: one is PS incorporating HG (AJCC PS), and the other is PS incorporating $\mathrm{NG}$ instead of $\mathrm{HG}$ (PS-NG). $\mathrm{HG}$ was given according to Nottingham modification of the Scarff-BloomRichardson scoring system [16]. NG was determined by the sum of the nuclear atypia score and the mitosis count score [8]. From the studies of early breast cancers, the prognostic impact was similar between NG and HG [17]. ER and PgR were assessed by immunohistochemistry and defined as positive if $1 \%$ or higher of the constituent carcinoma cells were immunoreactive [18]. HER2 status was assessed according to the 2013 American Society of Clinical Oncology (ASCO)/College of American Pathologists (CAP) guidelines [19]. Ki-67 labeling index was judged as high if $\geq 14 \%$ and low if $>14 \%$ of cancer cells according to the Breast Cancer Working Group [20] [21]. Pathological stages, i.e., pathological AS and pathological PS, were determined based on the clinical and pathological recording of breast cancer recommended by the Union for International Cancer Control (UICC) 8th edition and AJCC 8th edition, respectively.

\section{Statistical analysis according to prognosis}

Statistical differences were tested using the Chi-square test or Fisher's exact test. The Kaplan-Meier curves for relapsefree survival (RFS) and overall survival (OS) were drawn, and their differences were tested using the log-rank test. The hazard ratio of the parameters of recurrence or death was calculated using the Cox's univariate proportional hazard model. The independent significance of these parameters was tested using the Cox's multivariate proportional hazard model. All statistical analyses were two sided, and a $P$ value of $<0.05$ was considered significant. For the comparison among three groups or more, the $P$ values were adjusted using the Bonferroni correction.

To assess the goodness of fit of a model, the Akaike information criterion (AIC) was used [22]. The better model was 
considered to acquire a lower AIC value. The Harrell concordance index (C-index), which measures the proportion of pairs for which the predicted and observed outcomes are concordant, was used to measure the model's prognosis predicting performance [23]. The model with a higher C-index was considered to have a better predictive performance. All statistical analyses were performed using JMP ${ }^{\circledR} 14$ (SAS Institute Inc., Cary, NC, USA).

\section{Ethical approval and consent to participate}

This study was performed in accordance with the Declaration of Helsinki and was approved by the institutional review board of National Defense Medical College (registration number: 3003). All patients agreed to participate in this study, and a written informed consent was obtained from all patients.

\section{Results}

\section{Patient characteristics}

From the 800 patients, we acquired the data of sex, age, pathological tumor size, pathological tumor invasion size, pT, pN, lymphatic invasion, HG, NG, ER, PgR, HER2 status, Ki-67 labeling index, histological type, pathological UICC AS, pathological AJCC PS, pathological PS-NG, procedure (breast and axillary lymph node), medication therapy (endocrine therapy, chemotherapy, and anti-HER2 therapy), radiation therapy, relapse-free survival rate, and overall survival rate (Table 1). The pathological $\mathrm{T}$ factors were $\mathrm{pT} 1$ in $489(61.1 \%)$, pT2 in $273(34.1 \%)$, and pT3 in 38 (4.7\%).

Pathological AJCC PS of the patients was I in 535 (66.8\%), II in 163 (20.4\%), and III in 102 (12.8\%). Pathological UICC AS of the patients was I in 401 (50.1\%), II in $324(40.5 \%)$, and III in 75 (9.4\%). The ratio of patients with AJCC PS stage I and stage III was significantly higher than that with UICC AS stage I and stage III $(P<0.0001)$.

Pathological PS-NG of the patients was I in 534 (66.7\%), II in $159(19.9 \%)$, and III in $107(13.4 \%)$. The ratio of patients with PS-NG stage I and stage III was significantly higher than that with UICC AS stage I and stage III $(P<0.0001)$.

Of the 800 patients, the 5-year and 10-year RFS rates were 89.5 and $82.8 \%$, respectively (median follow-up 5.5 years), and the 5-year and 10-year OS rates were 96.0 and $88.5 \%$, respectively (median follow-up 6.0 years).

\section{Comparison of survival curves}

The RFS and OS curves of all 800 patients, stratified by AJCC PS, PS-NG, and UICC AS are shown in Fig. 1. Both RFS and OS curves were significantly different among the AJCC PS I, II, and III groups ( $P<0.0001$, each) (Fig. 1a, b). In AJCC PS I, II, and III groups, the 5-year RFS rates were $95.6,86.5$, and $64.8 \%$, respectively, while the 10 -year RFS rates were $89.7,79.6$, and $54.8 \%$, respectively. Likewise, in AJCC PS I, II, and III groups, the 5-year OS rates were $98.7,95.5$, and $84.3 \%$, respectively, while the 10 -year OS rates were $94.2,84.8$, and $69.5 \%$, respectively. With regard to AJCC PS, the AIC and the C-index for RFS were 1184.8 and 0.730 , and those for OS were 629.8 and 0.736 , respectively.

In the same way, both RFS and OS curves were significantly different among the PS-NG I, II, and III groups $(P<0.0001$, each) (Fig. 1c, d). In PS-NG I, II, and III groups, the 5-year RFS rates were 95.6, 86.2, and 66.5\%, respectively, while the 10-year RFS rates were 89.7, 79.1, and $57.1 \%$, respectively. Likewise, in PS-NG I, II, and III groups, the 5-year OS rates were 98.7, 95.4, and $85.0 \%$, respectively, while the 10-year OS rates were 94.2, 84.3, and $71.0 \%$, respectively. With regard to PS-NG, the AIC and the C-index for RFS were 1188.4 and 0.727 , and those for OS were 631.5 and 0.733 , respectively.

There was a significant difference in the RFS and OS curves among the AS I, II, and III groups $(P<0.0001$, each) (Fig. 1e, f). In UICC AS I, II, and III groups, the 5-year RFS rates were 95.4, 89.1, and 59.9\%, respectively, while the 10-year RFS rates were $91.8,80.8$, and $44.7 \%$, respectively. Likewise, in AS I, II, and III groups, the 5-year OS rates were $98.3,95.0$, and $88.2 \%$, respectively, while the 10-year OS rates were $94.9,86.6$, and $65.4 \%$, respectively. With regard to the UICC AS, the AIC and the C-index for RFS were 1192.9 and 0.699 , while those for OS were 645.1 and 0.679 , respectively. The AICs were lower and the $\mathrm{C}$ indices were higher in AJCC PS groups and in PS-NG groups than in the UICC AS groups.

The RFS and OS curves of 672 patients with invasive carcinoma of no special types (invasive ductal carcinoma), stratified with AJCC PS, PS-NG, and UICC AS, are shown in Fig. 2. In the 672 cases stratified with the AJCC PS, the AIC and the C-index for RFS were 985.9 and 0.724 , while those for OS were 524.4 and 0.735 , respectively. For these 672 cases stratified with the PS-NG, the AIC and the C-index for RFS were 989.3 and 0.720 , while those for OS were 526.1 and 0.731 , respectively. On the other hand, with regard to the stratification with UICC AS, the AIC and the C-index for RFS were 998.3 and 0.685 , while those for OS were 536.6 and 0.680 , respectively. The AICs were lower and the $\mathrm{C}$ indices were higher in AJCC PS groups or in PS-NG groups than in the UICC AS groups. 
Table 1 Patients characteristics

\begin{tabular}{|c|c|c|}
\hline \multirow{2}{*}{$\begin{array}{l}\text { Parameter } \\
\text { Total }\end{array}$} & \multicolumn{2}{|c|}{ Number of cases $(\%)$} \\
\hline & 800 & $(100.0)$ \\
\hline \multicolumn{3}{|l|}{ Sex } \\
\hline Male & 6 & $(0.8)$ \\
\hline Female & 794 & $(99.2)$ \\
\hline \multicolumn{3}{|l|}{ Age (year) } \\
\hline Mean \pm SD (range) & $60.6 \pm 12.0$ & $(24-91)$ \\
\hline$\geq 45$ & 704 & $(88.0)$ \\
\hline$<45$ & 96 & $(12.0)$ \\
\hline \multicolumn{3}{|l|}{ Pathological tumor size (mm) } \\
\hline Mean \pm SD (range) & $34.4 \pm 22.3$ & $(0.8-150.0)$ \\
\hline \multicolumn{3}{|l|}{ Pathological tumor invasive size (mm) } \\
\hline Mean \pm SD (range) & $21.0 \pm 16.6$ & $(0.1-150.0)$ \\
\hline \multicolumn{3}{|l|}{ Pathological T factor } \\
\hline pT1 & 489 & $(61.1)$ \\
\hline pT2 & 273 & $(34.1)$ \\
\hline pT3 & 38 & $(4.8)$ \\
\hline \multicolumn{3}{|l|}{ Pathological $\mathrm{N}$ factor } \\
\hline pN0 & 559 & $(69.9)$ \\
\hline $\mathrm{pN} 1$ & 176 & $(22.0)$ \\
\hline $\mathrm{pN} 2$ & 37 & $(4.6)$ \\
\hline $\mathrm{pN} 3$ & 28 & $(3.5)$ \\
\hline \multicolumn{3}{|l|}{ Lymphatic invasion } \\
\hline Positive & 375 & $(46.9)$ \\
\hline Negative & 425 & $(53.1)$ \\
\hline \multicolumn{3}{|l|}{ Histological grade } \\
\hline Grade I & 271 & $(33.9)$ \\
\hline Grade II & 250 & $(31.3)$ \\
\hline Grade III & 279 & $(34.8)$ \\
\hline \multicolumn{3}{|l|}{ Nuclear grade } \\
\hline Grade 1 & 270 & $(33.8)$ \\
\hline Grade 2 & 220 & $(27.5)$ \\
\hline Grade 3 & 310 & $(38.7)$ \\
\hline \multicolumn{3}{|l|}{ Estrogen receptor } \\
\hline Positive & 636 & $(79.5)$ \\
\hline Negative & 164 & $(20.5)$ \\
\hline \multicolumn{3}{|l|}{ Progesterone receptor } \\
\hline Positive & 565 & $(70.6)$ \\
\hline Negative & 235 & $(29.4)$ \\
\hline \multicolumn{3}{|l|}{ HER2 } \\
\hline Positive & 97 & $(12.1)$ \\
\hline Negative & 703 & $(87.9)$ \\
\hline \multicolumn{3}{|l|}{ Ki-67 labeling index (\%) } \\
\hline Mean \pm SD (range) & $16.8 \pm 16.1$ & $(0.0-90.0)$ \\
\hline$\geq 14$ & 329 & $(41.1)$ \\
\hline$<14$ & 435 & $(54.4)$ \\
\hline No data & 36 & $(4.5)$ \\
\hline \multicolumn{3}{|l|}{ Histological type } \\
\hline Invasive carcinoma of no special type (Invasive ductal carcinoma) & 672 & $(83.9)$ \\
\hline Invasive lobular carcinoma & 51 & $(6.4)$ \\
\hline Tubular carcinoma & 2 & $(0.3)$ \\
\hline
\end{tabular}


Table 1 (continued)

\begin{tabular}{|c|c|c|}
\hline \multirow{2}{*}{$\begin{array}{l}\text { Parameter } \\
\text { Total }\end{array}$} & \multicolumn{2}{|c|}{ Number of cases $(\%)$} \\
\hline & 800 & $(100.0)$ \\
\hline Mucinous carcinoma & 32 & $(4.0)$ \\
\hline Invasive micropapillary carcinoma & 9 & $(1.1)$ \\
\hline Carcinoma with apocrine differentiation (apocrine carcinoma) & 21 & $(2.6)$ \\
\hline Metaplastic carcinoma & 7 & $(0.9)$ \\
\hline Carcinoma with medullary features (medullary carcinoma) & 3 & $(0.4)$ \\
\hline Adenoid cystic carcinoma & 1 & $(0.1)$ \\
\hline Paget disease & 2 & $(0.3)$ \\
\hline \multicolumn{3}{|l|}{ UICC AS } \\
\hline I & 401 & $(50.1)$ \\
\hline II & 324 & $(40.5)$ \\
\hline III & 75 & $(9.4)$ \\
\hline \multicolumn{3}{|l|}{ AJCC PS } \\
\hline I & 535 & $(66.8)$ \\
\hline II & 163 & $(20.4)$ \\
\hline III & 102 & $(12.8)$ \\
\hline \multicolumn{3}{|l|}{ PS using nuclear grade (PS-NG) } \\
\hline I & 534 & $(66.7)$ \\
\hline II & 159 & $(19.9)$ \\
\hline III & 107 & $(13.4)$ \\
\hline \multicolumn{3}{|l|}{ Procedure (breast) } \\
\hline Mastectomy & 468 & $(58.5)$ \\
\hline Breast conserving surgery & 332 & $(41.5)$ \\
\hline \multicolumn{3}{|l|}{ Procedure (axillary lymph node) } \\
\hline SNB & 519 & $(64.8)$ \\
\hline $\mathrm{SNB} \rightarrow \mathrm{Ax}$ & 139 & $(17.4)$ \\
\hline $\mathrm{Ax}$ & 135 & $(16.9)$ \\
\hline No therapy & 7 & $(0.9)$ \\
\hline \multicolumn{3}{|l|}{ Endocrine therapy } \\
\hline Yes & 572 & $(71.5)$ \\
\hline No & 185 & $(23.1)$ \\
\hline No data & 43 & $(5.4)$ \\
\hline \multicolumn{3}{|l|}{ Chemotherapy } \\
\hline Yes & 277 & $(34.6)$ \\
\hline No & 486 & $(60.8)$ \\
\hline No data & 37 & $(4.6)$ \\
\hline \multicolumn{3}{|l|}{ Anti-HER2 therapy } \\
\hline Yes & 19 & $(2.4)$ \\
\hline No & 744 & $(93.0)$ \\
\hline No data & 37 & $(4.6)$ \\
\hline \multicolumn{3}{|l|}{ Radiation therapy } \\
\hline Residual breast irradiation & 278 & $(34.8)$ \\
\hline Postmastectomy radiation therapy & 35 & $(4.4)$ \\
\hline Not done & 455 & $(56.8)$ \\
\hline No data & 32 & $(4.0)$ \\
\hline \multicolumn{3}{|l|}{ Relapse-free survival rate (\%) } \\
\hline 5-year & 89.5 & \\
\hline 10-year & 82.8 & \\
\hline \multicolumn{3}{|l|}{ Overall survival rate (\%) } \\
\hline 5-year & 96 & \\
\hline
\end{tabular}


Table 1 (continued)

\begin{tabular}{lll}
\hline Parameter & \multicolumn{2}{l}{ Number of cases (\%) } \\
Total & 800 & $(100.0)$ \\
\hline 10 -year & 88.5 \\
\hline
\end{tabular}

Ax axillary lymph node dissection, AJCC PS American Joint Committee on Cancers prognostic stage, ER estrogen receptor, HER2 human epidermal growth factor receptor 2, $S D$ standard deviation, $S N B$ sentinel lymph node biopsy, UICC AS Union for International Cancer Control anatomical staging

\section{Univariate and multivariate analyses}

Cox's univariate analyses were performed to estimate the risk of recurrence in patients with the following six clinicopathological parameters: pT, pN, HG, ER, PgR, and HER2 (Table 2). Of these, four parameters (pT, pN, HG, and PgR) were significant risk factors of recurrence $(P<0.0001,<0.0$ $001,<0.0001$, and 0.0310 , respectively). ER only showed a marginal significance $(P=0.0729)$. In the Cox's multivariate analysis including the parameters that were significant in the univariate analyses, $\mathrm{pT}, \mathrm{pN}$, and $\mathrm{HG}$ were independent prognostic factors of RFS $(P=0.0003,<0.0001$, and $<0.0001$, respectively). Results from the same analyses including NG instead of HG showed almost the same results (Supplementary Table 1).

In the same way, Cox's univariate analyses were also performed to estimate the risk of death in patients with the aforementioned six clinicopathological parameters (Table 3). Of these, five parameters (pT, pN, HG, ER, and $\mathrm{PgR})$ were significant risk factors of death $(P<0.0001$, $0.0001,<0.0001,0.0156$, and 0.0092 , respectively). In the Cox's multivariate analysis including the parameters that were significant in univariate analyses, $\mathrm{pT}, \mathrm{pN}$, and $\mathrm{HG}$ were independent prognostic factors of OS $(P=0.0001,0.0193$, and 0.0244 , respectively). $\mathrm{PgR}$ was significant in the univariate analysis, but was excluded from the multivariate analysis because of its collinearity with ER. Results from the same analyses employing NG instead of HG showed almost the same results (Supplementary Table 2).

\section{Discordance between of UICC AS and AJCC PS}

Each UICC AS group was stratified by AJCC PS (Fig. 3). In the 401 patients at UICC AS I, 339 patients (84.5\%) were at AJCC PS I, 62 (15.5\%) patients were at AJCC PS II, and no patient was at AJCC PS III. In the 324 patients at UICC AS II, 190 patients (58.6\%) were at AJCC PS I, 87 (26.9\%) patients were at AJCC PS II, and 47 patients (14.5\%) were at AJCC PS III. In the 75 patients at UICC AS III, six patients $(8.0 \%)$ were at AJCC PS I, 14 patients (18.7\%) were at AJCC PS II, and 55 patients (73.3\%) were at AJCC PS III. The concordance rate in stage between AS and PS was $60.1 \%$. Results from the same analyses between UICC AS and PS-NG showed almost the same results (Supplementary
Fig. 1). The concordance rate in stage between AS and PS-NG was $59.6 \%$.

\section{Prognostic significance of AJCC PS-UICC AS discordance cases}

The RFS and OS curves for each UICC AS group stratified into AJCC PS groups are shown in Fig. 4. Of the 401 patients with UICC AS I, the AJCC PS II subgroup tended to show worse prognosis than the AJCC PS I subgroup in both RFS and OS ( $P=0.0512$ and $P=0.0883$, respectively), although the differences were not significant (Fig. 3a, b). Of the 324 patients with UICC AS II, the RFS and OS curves were significantly different between AJCC PS I and AJCC PS II + III subgroup ( $P=0.0003$ for RFS and $P<0.0001$ for OS) (Fig. 3c, d). Of the 75 patients with UICC AS III, there were no significant differences in both RFS and OS between the AJCC PS I+ II subgroup and AJCC PS III subgroup $(P=0.0948$ for RFS and $P=0.262$ for OS) (Fig. 3e, f). For UICC AS III, the lack in statistical differences might have been due in part to the small number of cases. Results from the same analyses using PS-NG instead of AJCC PS showed almost the same results (Supplementary Fig. 2).

\section{Discussion}

In the present study, we evaluated the usefulness of pathological AJCC PS for prediction of prognosis of primary breast cancer patients by comparing it with pathological UICC AS. First, we compared the number of cases at each stage (I, II, and III) between PS and AS. Second, we compared the survival curves of the patients at each stage (I, II, and III) between PS and AS, and tested the validity of PS compared with AS as a model and the model's predictive performance.

We were able to confirm that the biological factors including grade, ER, PgR, and HER2 were useful not only for the selection of appropriate adjuvant systemic therapies, but also for the prediction of patient's prognosis. The PS, which includes the AS and biological factors, appeared to be a useful model for stratifying the primary breast cancer patients into biologically distinct groups. The present results 

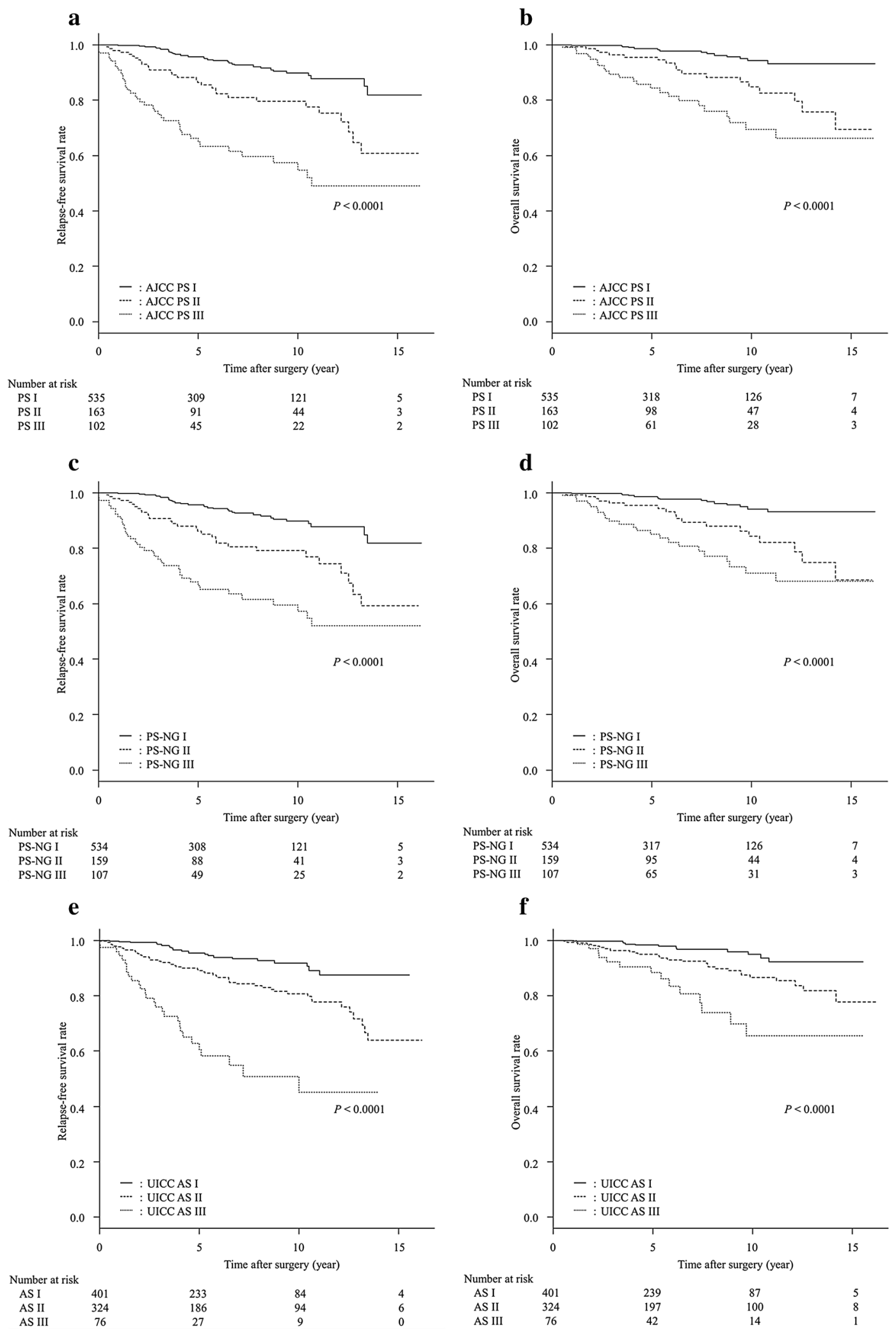

Fig. 1 Relapse-free survival (RFS) curves and overall survival (OS) curves of 800 patients with breast cancer stratified by (a, b) American Joint Committee on Cancer (AJCC) prognostic stage (PS), (c, d) PS using nuclear grade (NG) instead of histological grade (PS-NG),

and (e, f) Union for International Cancer Control (UICC) anatomical stage (AS). In a, c, e, three RFS curves were significantly different $(P<0.0001$, each $)$. In $\mathbf{b}, \mathbf{d}, \mathbf{f}$, three OS curves were significantly different $(P<0.0001$, each $)$ 

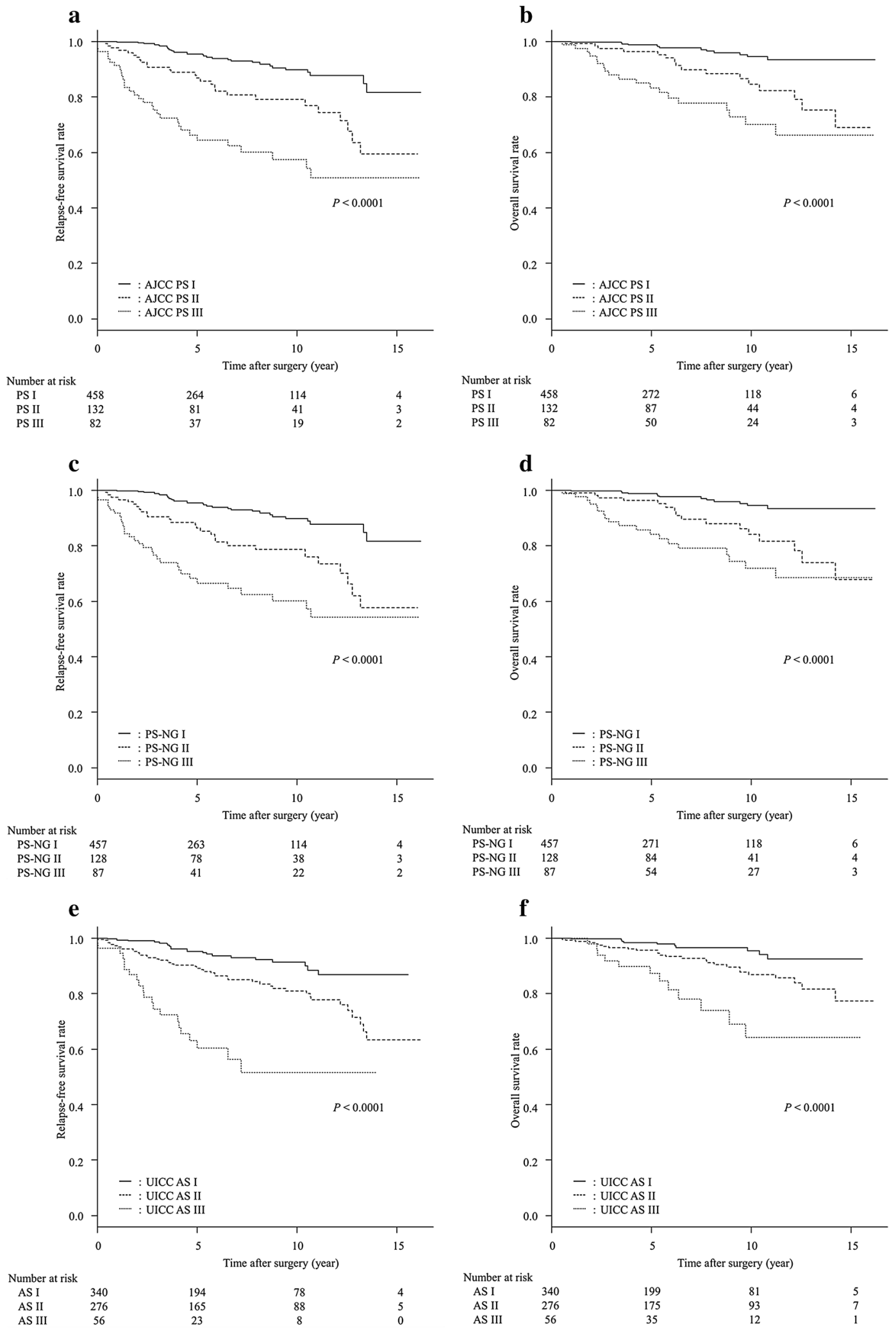

Fig. 2 Relapse-free survival (RFS) curves and overall survival (OS) curves of 672 patients with invasive carcinoma of no special type stratified by (a, b) American Joint Committee on Cancer (AJCC) prognostic stage (PS), (c, d) PS using nuclear grade (NG) instead of

histological grade (PS-NG), and (e, f) Union for International Cancer Control (UICC) anatomical stage (AS). In a, c, e, three RFS curves were significantly different $(P<0.0001$, each). In $\mathbf{b}, \mathbf{d}$, f, three OS curves were significantly different $(P<0.0001$, each) 
Table 2 Results of the Cox's univariate and multivariate proportional hazard model analyses using clinicopathological factors for relapse-free survival $(n=800)$

\begin{tabular}{|c|c|c|c|c|c|c|}
\hline \multirow[t]{2}{*}{ Parameter (unfavorable vs. favorable) } & \multicolumn{3}{|c|}{ Univariate analysis } & \multicolumn{3}{|c|}{ Multivariate analysis } \\
\hline & Hazard ratio & $95 \% \mathrm{CI}$ & $P$ value & Hazard ratio & $95 \% \mathrm{CI}$ & $P$ value \\
\hline Pathological T factor (pT2, pT3 vs. pT1) & 3.52 & $2.35-5.40$ & $<0.0001$ & 2.24 & $1.44-3.53$ & 0.0003 \\
\hline Pathological N factor (pN3 vs. pN0, pN1, pN2) & 8.98 & $5.04-15.0$ & $<0.0001$ & 4.46 & $2.44-7.75$ & $<0.0001$ \\
\hline Histological grade (Grade III vs. Grade I, Grade II) & 3.64 & $2.44-5.53$ & $<0.0001$ & 2.55 & $1.63-4.05$ & $<0.0001$ \\
\hline Estrogen receptor (negative vs. positive) & 1.50 & $0.96-2.28$ & 0.0729 & & & \\
\hline Progesterone receptor (negative vs. positive) & 1.56 & $1.04-2.31$ & 0.0310 & 1.04 & $0.68-1.58$ & 0.865 \\
\hline HER2 (positive vs. negative) & 1.11 & $0.62-1.86$ & 0.713 & & & \\
\hline
\end{tabular}

CI confidence interval, HER2 human epidermal growth factor receptor 2

Table 3 Results of the Cox's univariate and multivariate proportional hazard model analyses using clinicopathological factors for overall sur$\operatorname{vival}(n=800)$

\begin{tabular}{|c|c|c|c|c|c|c|}
\hline \multirow[t]{2}{*}{ Parameter (unfavorable vs. favorable) } & \multicolumn{3}{|c|}{ Univariate analysis } & \multicolumn{3}{|c|}{ Multivariate analysis } \\
\hline & Hazard ratio & $95 \% \mathrm{CI}$ & $P$ value & Hazard ratio & $95 \% \mathrm{CI}$ & $P$ value \\
\hline Pathological T factor (pT2, pT3 vs. pT1) & 4.58 & $2.56-8.70$ & $<0.0001$ & 3.22 & $1.74-6.30$ & 0.0001 \\
\hline Pathological $\mathrm{N}$ factor (pN3 vs. pN0, pN1, pN2) & 5.44 & $2.49-10.6$ & 0.0001 & 2.67 & $1.19-5.40$ & 0.0193 \\
\hline Histological grade (Grade III vs. Grade I, Grade II) & 3.54 & $2.05-6.36$ & $<0.0001$ & 2.04 & $1.10-3.90$ & 0.0244 \\
\hline Estrogen receptor (negative vs. positive) & 2.02 & $1.15-3.45$ & 0.0156 & 1.37 & $0.75-2.45$ & 0.297 \\
\hline Progesterone receptor (negative vs. positive) & 2.04 & $1.20-3.45$ & 0.0092 & & & \\
\hline HER2 (positive vs. negative) & 1.21 & $0.55-2.36$ & 0.606 & & & \\
\hline
\end{tabular}

CI confidence interval, HER2 human epidermal growth factor receptor 2
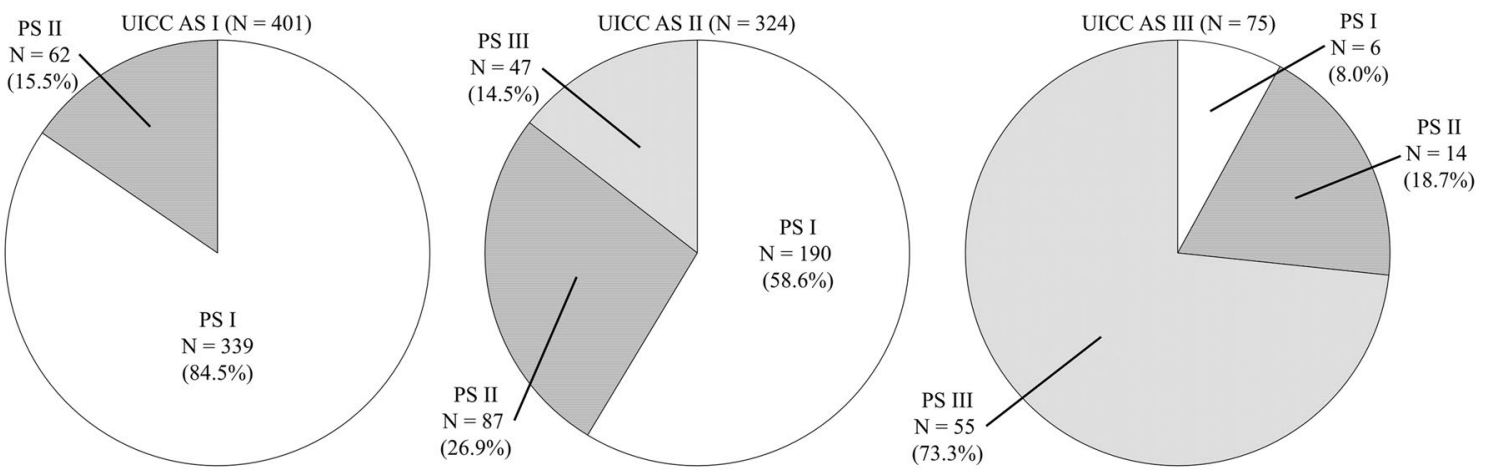

Fig. 3 Concordance between Union for International Cancer Control (UICC) anatomical stage (AS) and the American Joint Committee on Cancer (AJCC) prognostic stage (PS). In UICC AS I patient group and AS III patient group, the stages were concordant in 84.5

were similar to those reported by Abdel-Rahman et al. [24] and Li et al. [25].

The majority (84.5\%) of AS I cases were concordant with PS I cases. Likewise, the majority (73.3\%) of AS III were concordant with PS III cases. By contrast, the situation was different for stage II: of the 324 patients with AS II, 87 had PS II, and the concordance rate between AS II and PS II was only $26.9 \%$. In other words, the number of PS I cases and $73.3 \%$ of cases between AS and PS, respectively. By contrast, in UICC AS II group, the stage was discordant between AS and PS in $73.1 \%$ of cases

was 1.33 folds (535 vs. 401) as high as that of AS I, and the number of cases of PS III was 1.36 folds (102 vs. 75 ) as high as that of AS III. Nonetheless, between PS and AS, the survival curves of patients with stages I, II, and III were almost similar (Fig. 1).

The number of AS II cases was 1.99 folds (324 vs. 163 ) as high as that of PS II. In patients with AS II, the subgroups stratified by PS, i.e., PS I PS II, and PS III 

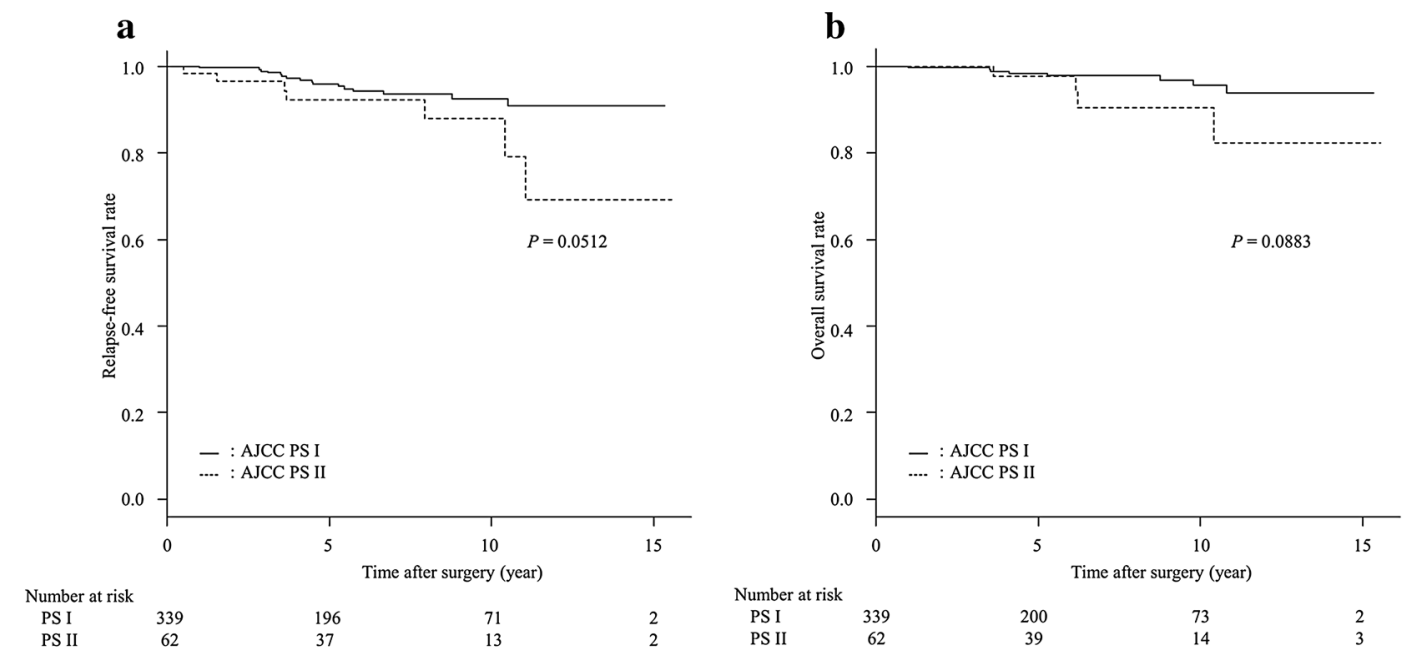

c

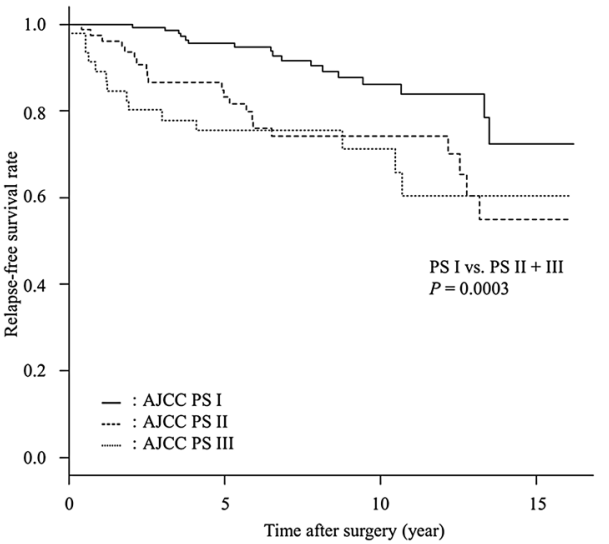

$\begin{array}{lllll}\text { Number at risk } & & 11 & 50 & 3 \\ \text { PS I } & 190 & 50 & 30 & 1 \\ \text { PS II } & 87 & 25 & 14 & 2 \\ \text { PS III } & 47 & & \end{array}$

e

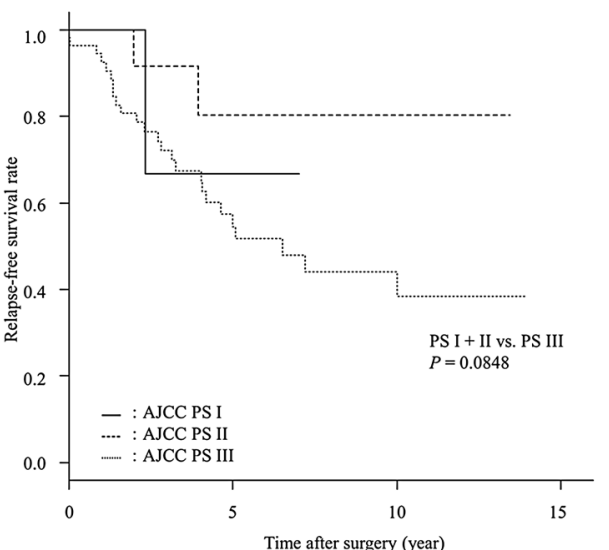

Time after surgery (year)

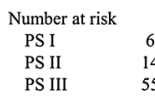

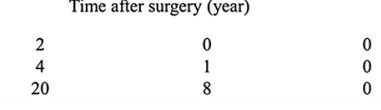

subgroups, showed significantly different RFS and OS curves. Therefore, many patients who should be classified as having stage I and stage III appeared to have been

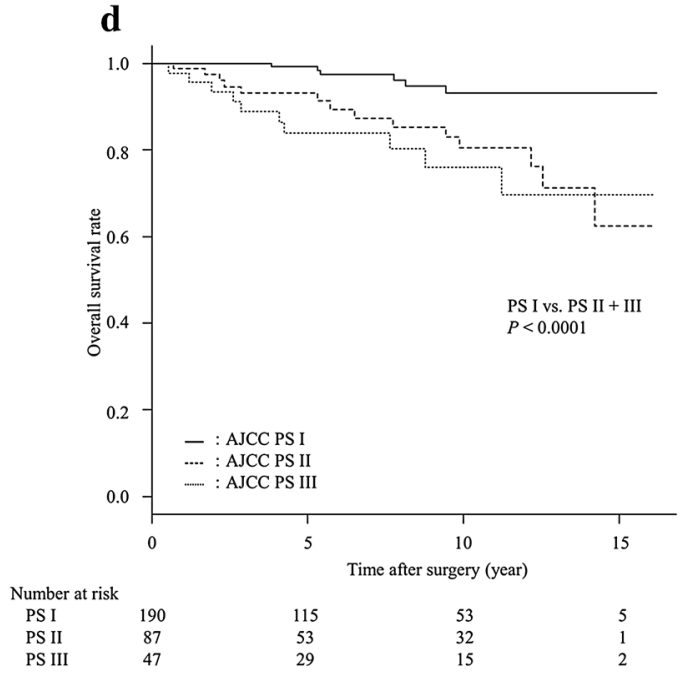

f

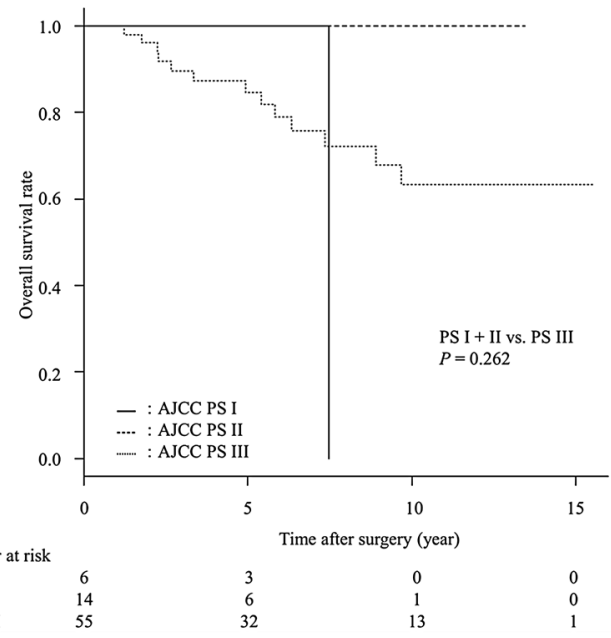

included in the AS II group. Furthermore, in patients with AS I, the subgroups stratified by PS, i.e., PS I and PS II subgroups, showed nearly significant difference in RFS 
४Fig. 4 The relapse-free survival (RFS) curves (a) and overall survival (OS) curves (b) of 401 patients with UICC AS I breast cancer stratified by AJCC PS status. a Curves for AJCC PS I and PS II subgroups tended to differ but were not of statistical significance $(P=0.0512)$. b Curves tended to differ but were not of statistical significance $(P=0.0883)$. The RFS curves $(\mathbf{c})$ and OS curves $(\mathbf{d})$ for 324 patients with UICC AS II breast cancer stratified by AJCC PS status. (c) RFS curves were significantly different between AJCC PS I subgroup and PS II + III subgroup $(P=0.0003)$. d OS curves were significantly different between AJCC PS I subgroup and PS II+III subgroup $(P<0.0001)$. The RFS curves $(\mathbf{e})$ and OS curves (f) of 75 patients with UICC AS III breast cancer stratified by AJCC PS status. e Curves for AJCC PS I+ II subgroup and PS III subgroup tended to differ but were not significant $(P=0.0848)$. $\mathbf{f}$ Curves did not differ significantly $(P=0.262)$

and OS curves. Therefore, a small proportion of patients who could be classified as having stage II was included in the AS I group.

To trichotomize the patients according to RFS or OS, the PS classification system appeared to be a more accurate tool in stratifying patients than the AS classification system. The results shown in Fig. 4 exemplified this speculation. For example, in the AS II group, the prognosis of PS I subgroup was obviously better than that of the PS II + III subgroup and was similar to that of the UICC AS I patients. Likewise, even in the AS I group, the prognosis of PS II subgroup tended to be poorer than that of the PS I subgroup, although the difference was not significant (Fig. 3a, b). Furthermore, in the AS III group, the curves for PS III subgroup and PS II subgroup appeared to be different, although the difference was not significant (Fig. 3e, f). These findings were confirmed statistically using the AIC and C-index.

Because NG as well as HG has been used in Japan, we also evaluated PS using NG instead of HG. Prognostic values, differences in survival curves among stages, AIC and C-index of PS-NG were very similar with those of AJCC PS. Therefore, it appeared that PS classification employing NG was not inferior to AJCC PS for patient prognostication. NG is registered in the National Clinical Database of breast cancer in Japan but HG is not. In large scale studies, PS using NG might be able to a surrogate for AJCC PS for the comparison between PS and AS.

This study has some limitations. It is a retrospective study that was conducted in a single facility using a relatively small number of samples. We had to exclude many cases from the study because of various reasons described in the methods. Nonetheless, we were able to show that PS was a valid model for prognostication of breast cancer patients into biologically distinct groups. However, further multicenter and prospective studies are needed to confirm the effectiveness of AJCC PS.

\section{Conclusion}

We studied the prognostic significance of AJCC PS classification in patients with primary breast cancer. AJCC PS showed lower AIC and higher C-index than UICC AS in both RFS and OS. For the prognostication of surgically resectable primary breast cancers, AJCC PS appeared to be used in the stratification of these cases more appropriately than UICC AS.

Acknowledgements Data extraction and data analysis were supported in part by JSPS KAKENHI (Grant number: JP 18K07340). JSPS did not influence the study design, data collection, data analysis, data interpretation, and the writing of the manuscript.

Author contributions RT, YY, and HT performed the planning, acquired and analyzed data, and wrote the manuscript. YY, ToK, MK, TE, and TY (breast surgeons) performed the surgery and collected the clinical data. RT, YY, TaK (pathologist), and HT (pathologist) collected the pathological data. HU and YK participated in its design and coordination in co-operation with RT, YY, and HT. All authors read and approved the final manuscript.

\section{Compliance with ethical standards}

Conflict of interests Dr. Einama reports personal fees from Eisai Co., outside the submitted work; Dr. Yamasaki reports Grants from Japan Society for the Promotion of Science, Novartis Pharma K.K., and Eisai Co., personal fees from Astrazeneca Co., Bristol-Meyers Squibb Co., Eisai Co., outside the submitted work; Dr. Kishi reports grants from Taiho Pharmaceutical Co., LTD, Japan Agency for Medical Research and Development, Eisai Co., LTD, Yakult Co., LTD, and Pfizer Co., LTD, personal fees from Yakult Co., LTD, Pfizer Co., LTD, DaiichiSankyo Co., LTD, Mylan Co., LTD, and Astrazeneca Co., LTD, outside the submitted work; Dr. Tsuda reports grants from Chugai Pharmaceutical Co., and Taiho Pharmaceutical Co., personal fees from Roche Diagnostics Co., from Konica Minolta Co., from Eisai Co., from Astrazeneca Co., and Bristol-Meyers Squibb Co., outside the submitted work. The other authors declare that they have no competing interests.

Research involving human participants The study was approved by the institutional review board of National Defense Medical College.

Informed consent All patients agreed to participate in this study, and a written informed consent was obtained from all patients.

Open Access This article is licensed under a Creative Commons Attribution 4.0 International License, which permits use, sharing, adaptation, distribution and reproduction in any medium or format, as long as you give appropriate credit to the original author(s) and the source, provide a link to the Creative Commons licence, and indicate if changes were made. The images or other third party material in this article are included in the article's Creative Commons licence, unless indicated otherwise in a credit line to the material. If material is not included in the article's Creative Commons licence and your intended use is not permitted by statutory regulation or exceeds the permitted use, you will need to obtain permission directly from the copyright holder. To view a copy of this licence, visit http://creativecommons.org/licenses/by/4.0/. 


\section{References}

1. Fitzmaurice C, Dicker D, Pain A, Hamavid H, Moradi-Lakeh M, MacIntyre MF, et al. The global burden of cancer 2013. JAMA Oncol. 2015;1:505-27. https://doi.org/10.1001/jamao ncol.2015.0735.

2. Hortobagyi GM, Connolly JL, D'Orsi CJ, Edge SB, Mittendorf EA, Rugo HS, et al. Breast. In: Amin MB, Edge SB, Greene FL, Byrd DR, Brookland RK, Washington MK, et al., editors. AJCC cancer staging manual. 8th ed. New York: Springer; 2016. p. 589-628.

3. Gradishar WJ, Anderson BO, Balassanian R, Blair SL, Burstein HJ, Cyr A, et al. Breast cancer version 2.2015. J Natl Compr Canc Netw. 2015;13:448-75. https://doi.org/10.6004/jnccn.2015.0060.

4. Goldhirsch A, Wood WC, Gelber RD, Coates AS, Thürlimann B, Senn HJ. Progress and promise: highlights of the international expert consensus on the primary therapy of early breast cancer 2007. Ann Oncol. 2007;18:1133-44. https://doi.org/10.1093/ annonc/mdm271.

5. Black MM, Opler SR, Speer FD. Survival in breast cancer cases in relation to the structure of the primary tumor and regional lymph nodes. Surg Gynecol Obstet. 1955;100:543-51.

6. Elston CW, Ellis IO. Pathological prognostic factors in breast cancer. I. The value of histological grade in breast cancer: experience from a large study with long-term follow-up. Histopathology. 1991;19:403-10. https://doi.org/10.1111/j.1365-2559.1991.tb002 29.x.

7. Elston EW, Ellis IO. Method for grading breast cancer. J Clin Pathol. 1993;46:189-90. https://doi.org/10.1136/jcp.46.2.189-b.

8. Tsuda H, Akiyama F, Kurosumi M, Sakamoto G, Watanabe T. Establishment of histological criteria for high-risk node-negative breast carcinoma in a randomized clinical trial of adjuvant therapy. Japan national surgical adjuvant study of breast cancer (NSAS-BC) pathology section. Jpn J Clin Oncol. 1998;28:486-91. https://doi.org/10.1093/jjco/28.8.486.

9. Davies C, Godwin J, Gray R, Clarke M, Cutter D, Darby S, et al. Relevance of breast cancer hormone receptors and other factors to the efficacy of adjuvant tamoxifen: patient-level meta-analysis of randomised trials. Lancet. 2013;378:771-84. https://doi. org/10.1016/S0140-6736(11)60993-8.

10. Barnes DM, Harris WH, Smith P, Millis RR, Rubens RD. Immunohistochemical determination of oestrogen receptor: comparison of different methods of assessment of staining and correlation with clinical outcome of breast cancer patients. Br J Cancer. 1996;74:1445-511. https://doi.org/10.1038/bjc.1996.563.

11. Slamon D, Eiermann W, Robert N, Pienkowski T, Martin M, Press $\mathrm{M}$, et al. Adjuvant trastuzumab in HER2-positive breast cancer. N Engl J Med. 2011;365:1273-83. https://doi.org/10.1056/NEJMo a0910383.

12. Moasser MM, Krop IE. The evolving landscape of HER2 targeting in breast cancer. JAMA Oncol. 2015;1:1154-61. https://doi. org/10.1001/jamaoncol.2015.2286.

13. Van Poznak C, Somerfield MR, Bast RC, Cristofanilli M, Goetz MP, Gonzalez-Angulo AM, et al. Use of biomarkers to guide decisions on systemic therapy for women with metastatic breast cancer: American society of clinical oncology clinical practice guideline. J Clin Oncol. 2015;33:2695-704. https://doi.org/10.1200/ JCO.2015.61.1459.

14. Rakha EA, Allison K, Ellis I, Horii R, Masuda S, Penault-Llorca $\mathrm{F}$, et al. Invasive breast carcinoma: general overview. In: WHO
Classification of Tumours Editorial Board, editor. Breast tumours WHO classification of tumours. 5th Ed. Lyon: World Health Organization; pp. 82-101.

15. Japanese Breast Cancer Society. General rules for clinical and pathological recording of breast cancer. 18th ed. Tokyo: Kanehara Shuppan; 2018. p. 68-75.

16. Rakha EA, Reis-Filho JS, Baehner F, Dabbs DJ, Decker T, Eusebi V, et al. Breast cancer prognostic classification in the molecular era: the role of histological grade. Breast Cancer Res. 2010;12:207. https://doi.org/10.1186/bcr2607.

17. Ono M, Tsuda H, Yunokawa M, Yonemori K, Shimizu C, Tamura K, Kinoshita T, Fujiwara Y. Prognostic impact of Ki-67 labeling indices with 3 different cutoff values, histological grade, and nuclear grade in hormone-receptor-positive, HER2-negative, node-negative invasive breast cancers. Breast Cancer. 2015;22(2):141-52. https://doi.org/10.1007/s12282-013-0464-4.

18. Hammond ME, Hayes DF, Dowsett M, Allred DC, Hagerty KL, Badve S, et al. American society of clinical oncology/college of American pathologists guideline recommendations for immunohistochemical testing of estrogen and progesterone receptors in breast cancer. J Clin Oncol. 2010;28:2784-95. https://doi. org/10.1043/1543-2165-134.7.e48.

19. Wolff AC, Hammond ME, Hicks DG, Dowsett M, McShane LM, Allison $\mathrm{KH}$, et al. Recommendations for human epidermal growth factor receptor 2 testing in breast cancer: American society of clinical oncology/college of American pathologists clinical practice guideline update. J Clin Oncol. 2013;31:3997-4013. https:// doi.org/10.1200/JCO.2013.50.9984.

20. Dowsett M, Nielsen TO, A'Hern R, Bartlett J, Coombes RC, Cuzick J, et al. Assessment of Ki67 in breast cancer: recommendations from the international Ki67 in breast cancer working group. J Natl Cancer Inst. 2011;103:1656-64. https://doi.org/10.1093/jnci/djr39 3.

21. Cheang MC, Chia SK, Voduc D, Gao D, Leung S, Snider J, et al. Ki67 index, HER2 status, and prognosis of patients with luminal B breast cancer. J Natl Cancer Inst. 2009;101:736-50. https://doi. org/10.1093/jnci/djp082.

22. Akaike H. A new look at the statistical model identification. IEEE Trans Aut Control. 1974; 19:716-23.

23. Kang L, Chen W, Petrick NA, Gallas BD. Comparing two correlated $\mathrm{C}$ indices with right-censored survival outcome: a one-shot nonparametric approach. Stat Med. 2015;34:685-703. https://doi. org/10.1002/sim.6370.

24. Abdel-Rahman O. Validation of the 8th AJCC prognostic staging system for breast cancer in a population-based setting. Breast Cancer Res Treat. 2018;168:269-75. https://doi.org/10.1007/s1054 9-017-4577-x.

25. Li X, Zhang Y, Meisel J, Jiang R, Behera M, Peng L. Validation of the newly proposed American Joint Committee on Cancer (AJCC) breast cancer prognostic staging group and proposing a new staging system using the national cancer database. Breast Cancer Res Treat. 2018;171:303-13. https://doi.org/10.1007/ s10549-018-4832-9.

Publisher's Note Springer Nature remains neutral with regard to jurisdictional claims in published maps and institutional affiliations. 